\title{
Full-Scale Flexural Testing on Fiber-Reinforced Polymer (FRP) Poles
}

\author{
Slimane Metiche and Radhouane Masmoudi*
}

Department of Civil Engineering, Université de Sherbrooke, 2500, BLV de l'Université, Sherbrooke, QC J1K 2RI, Canada

\begin{abstract}
An extensive research project is currently carried out at the University of Sherbrooke to develop and evaluate the flexural behavior of lightweight fiber reinforced polymer (FRP) poles. In this project, a total of 23 full-scale prototypes of FRP poles with length ranging from 5 to $12 \mathrm{~m}$ were submitted to static flexural testing. The load carrying capacity, the failure modes and the deflection of these FRP poles, having hollow circular cross section and variable wall thickness, are being investigated experimentally and theoretically. The FRP poles were produced with the filament winding process, using epoxy resin reinforced with E-glass fibers. Each type of the poles tested in this study is constituted by three zones where the geometrical and the mechanical properties are different in each zone. The difference of these properties is due to the number of layers used in each zone and the fiber orientation of each layer. A new test setup designed and built according to ASTM-D4923-01 and ANSI-C136.20 standards recommendations was used to conduct full-scale flexural testing. Test parameters include the geometrical properties of FRP poles, the type of fibers, presence and positioning (compression side compared to tension side) of the hole are also investigated. Experimental results show that the use of low linear density glass-fibers could provide an increase of the ultimate load carrying capacity up to $38 \%$ for some FRP poles. Also, the positioning of the hole in the compression side compared to the tension side leads to an increase of the ultimate load carrying capacity up to $22 \%$ for the $5.4 \mathrm{~m}$ (18 feet) FRP poles and no significant effect $(3,5 \%)$ for the $12 \mathrm{~m}(40$ feet) FRP poles. This is mainly due to the stacking sequence and the stress states generated around the hole. Theoretical predictions of the deflection at the loading position are also presented using the theory of linear elasticity and the orthotropic material properties of the composite materials. Good agreement is found between experimental and theoretical results.
\end{abstract}

Keywords: Fiber Reinforced Polymers, FRP Structural Shapes, FRP poles, Flexural behavior, Filament Winding.

\section{INTRODUCTION}

The development of Fiber Reinforced Polymer (FRP) materials began in the 1940s for military and aerospace applications [1].

When the secret technology behind the so-called "stealth" military aircraft was disclosed, it became clear that advanced composite materials would have many potential applications in antenna supporting structures. Up to recent years, however, it was puzzling to observe that the telecommunications industry was not using these materials more widely. Advanced composites are also increasingly popular in electrical applications and current investigations on ceramic fibers indicate that their use will continue to grow [2].

Wide arrays of industries have found Fiber Reinforced Composites (FRC) the perfect substitute for traditional materials. Advanced paint and resin systems, have made FRC virtually maintenance free for generations to come [3].

FRP are becoming increasingly popular in the engineering applications as alternative to conventional engineering materials. The unique characteristics of FRP such as their light weight, their resistance to corrosion, and the lower cost of construction and maintenance, are very promising in the application of FRP in civil engineering [4].

\footnotetext{
*Address correspondence to this author at the Department of Civil Engineering, Université de Sherbrooke, 2500, BLV ${ }^{\mathrm{d}}$ de l'Université, Sherbrooke, QC J1K 2R1, Canada; Tel: 819-821-8000-63110; Fax: 819-821-7974; E-mail: Radhouane.masmoudi@usherbrooke.ca
}

The majority of the existing electrical poles in Canada as well as in the world are made from traditional materials such as wood, concrete or steel. The limitation in length of wooden poles and the vulnerability of steel or concrete poles to climatic aggressions have motivated the manufacturers and researchers to find alternatives.

The main objective of this research project is to study the full-scale flexural Behavior of fiber-reinforced polymer (FRP) tapered poles manufactured by the filament winding process, in order to optimize the design and to propose improvement of the manufacturing process.

While studies have addressed the material failure and buckling of thin-walled sections such as I-beams, box beams, etc., made from composite materials [5], very few studies have been conducted on the Behavior of tapered sections [6].

Zhi-Min Lin [4] investigated the Behavior of scaled FRP models of transmission poles under cantilever loading conditions. The four specimens tested were of prismatic circular hollow cross-section. The outside diameter of the poles was $76 \mathrm{~mm}$ and the wall thickness was $6 \mathrm{~mm}$. These were fabricated by filament winding strips of pultruded sheets arranged in circular pattern. According to the test results, a linear Behavior of the FRP poles was observed up to failure.

A report of lateral loading test, provided by Shakespeare Company [7] on $10.65 \mathrm{~m}$ length fiberglass pole, shows the minimal effective loss of strength due to the row of 22.23 $\mathrm{mm}$ diameter holes drilled in the side wall to climb the pole. The inner diameters of the specimen at the base and the top end were $216 \mathrm{~mm}$ and $127 \mathrm{~mm}$, respectively. A total of 22 
holes were drilled and spaced by $305 \mathrm{~mm}$. The first one was drilled at $2.13 \mathrm{~m}$ far from the base-end of the pole.

An experimental study was conducted at the California Department of Transportation on three different types of FRP poles, some with breakaway anchor base, direct burial breakaway joints, and non-breakaway anchor bases, (each type in lengths of $9140 \mathrm{~mm}$ and $10700 \mathrm{~mm}$ ), under cantilever loading conditions [8]. These different prototypes were obtained from two manufacturers of FRP lighting standards. Four parameters, including deflection of the pole tip under a specified bending load, ultimate bend strength, degradation of coating after 2500 hours of accelerated weathering, and coating thickness, were evaluated. Results were compared to the requirements of the California Department of Transportation 1992-Standard (Special Provision (SSP) 86.08.5 "Fiberglass Lighting Standards") [9]. According to this standard, the minimum strength of the $9140 \mathrm{~mm}$ length and the 10700 mm length is $2406 \mathrm{~N}$ and $2562 \mathrm{~N}$, respectively. The maximum deflection shall not exceed $13 \%$ of the free-length above ground at $2 / 3$ of the minimum bending load. From tests performed, it was determined that many poles of the different types failed to meet many of the California Department of Transportation (SSP) requirements. It was also observed that the service door is not the only zone of weakness for an FRP pole. The junction between the pole and its anchoring system constitutes also a zone of weakness.

Experimental and analytical studies were carried out [6] to validate the predicted ultimate loads for tapered filament wound FRP scaled poles subjected to cantilever bending. The specimens were $2500 \mathrm{~mm}$ in length; the inner diameters at the base and the top end were $100 \mathrm{~mm}$ and $74 \mathrm{~mm}$, respectively. The wall thickness varied depending on the number of layers, the results of this study show that the stiffness and the strength of FRP poles as well as the mode of failure depend mainly on their wall thickness. While a local buckling failure is observed for thin walled samples, compression and tension failures were observed for samples with more significant thicknesses.

The fiber orientation has a significant effect on the performance of FRP poles. The same performance of FRP poles having high fiber volume fraction can be achieved by using less fiber volume fraction but with changing the fiber orientation towards the longitudinal direction [6] and the incorporation of circumferential layers tend to increase the critical ovalization load [10]. More tests, however, are required to determine the optimum values of fiber angle and fiber volume fraction.
In this paper, the load carrying capacity and the flexural stiffness as well as the deflection of tapered fiber-reinforced polymer (FRP) poles with hollow circular cross section and variable wall thickness subjected to lateral loading are being investigated. In addition, the effect of the type of fibers as well as the presence and positioning of the hole (under tension or compression) on the flexural behavior of FRP poles is investigated.

The maximum deflection at the loading position as well as the flexural stiffness are determined theoretically and compared with experimental results. A total of twenty three full-scale FRP poles have been tested in flexure up to failure. A new test setup designed and built according to the recommendations described in ASTM [11] and ANSI [12] standards was used and is presented in this paper.

\section{EXPERIMENTAL PROGRAM}

\section{Test Prototypes}

The full-scale tapered FRP poles with hollow crosssection, made of epoxy resin reinforced with E-glass fibers, are produced by the filament winding process. The mechanical and physical properties of the fibers and the epoxy resin are presented in Table $\mathbf{1 .}$

The characteristics and configuration of the tested poles are presented in Table $\mathbf{2}$. A total of twenty three poles have been tested in flexural bending up to failure. Two types of fibers (Type A and Type B) are used to evaluate their effects on the flexural behavior. Note that the only difference between both types is the linear density, as shown in Table $\mathbf{1}$.

When the lighting pole is subjected to bending stresses experienced during heavy wind loading, the hole area, even though provided with additional fiberglass reinforcement, still remain a critical zone for bending failure. Since this location can be subjected to extreme tension or compression during severe wind loading, the presence and positioning (tension or compression side) of the hole are also evaluated. It should be mentioned that the FRP poles presented in this investigation are designed to be directly buried in the ground.

All the prototypes are identified as follows: From the left to the right: the first number indicates the total height of the pole in feet, the first letter indicates the type of fiber, the second number indicates the supported length in feet and the second letter indicates the hole positioning (in compression or in tension, the number zero means that the pole was tested without any hole above ground line), the latest number (in

Table1. Properties of Fibers and Resin

\begin{tabular}{|c|c|c|c|}
\hline Properties & Glass Fibers Type A & Glass Fibers Type B & Epoxy Resin \\
\hline \hline $\operatorname{Tex}^{(*)}(\mathrm{g} / \mathrm{km})$ & 1100 & 2000 & 1.2 \\
\hline Density $\left(\mathrm{g} / \mathrm{cm}^{3}\right)$ & 2.6 & 2.6 & 3.38 \\
\hline Modulus of elasticity $(\mathrm{GPa})$ & 80 & 30 & 1.6 \\
\hline Shear modulus (GPa) & 30 & 0.25 & 0.4 \\
\hline Poisson's ratio & 0.25 & 80 & \\
\hline
\end{tabular}

(*): In the fiber industry, it is common to specify fibers in units of tex, which indicates the weight in gram of a $1000 \mathrm{~m}$ long single fiber (linear density). 
Table 2. Characteristics and Configuration of the Tested Poles

\begin{tabular}{|c|c|c|c|c|c|c|c|c|c|}
\hline \multirow{2}{*}{\multicolumn{2}{|c|}{$\begin{array}{l}\text { Pole Id. And } \\
\text { samples }\end{array}$}} & \multirow{3}{*}{ 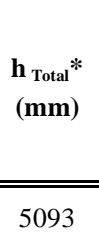 } & \multirow{3}{*}{$\begin{array}{c}\mathbf{h}_{\text {Supported }} \text { * } \\
(\mathbf{m m})\end{array}$} & \multirow{3}{*}{$\begin{array}{c}\begin{array}{c}\text { Bottom-Top di- } \\
\text { ameters (mm) }\end{array} \\
150-76\end{array}$} & \multicolumn{3}{|c|}{ Principal hole (AGL)** } & \multicolumn{2}{|c|}{ Underground hole (BGL)** } \\
\hline & & & & & \multirow{2}{*}{$\begin{array}{c}\begin{array}{c}\text { Dimensions } \\
(\mathbf{m m})\end{array} \\
64 \times 127\end{array}$} & \multirow{2}{*}{$\begin{array}{c}\begin{array}{c}\text { Location } \\
\text { (mm) }\end{array} \\
610\end{array}$} & \multirow{2}{*}{$\begin{array}{c}\text { Positioning } \\
\text { Comp. }\end{array}$} & \multirow{2}{*}{$\begin{array}{c}\begin{array}{c}\text { Dimensions } \\
(\mathbf{m m})\end{array} \\
\varnothing 64\end{array}$} & \multirow{2}{*}{$\begin{array}{c}\begin{array}{c}\text { Location } \\
\text { (mm) }\end{array} \\
305\end{array}$} \\
\hline 17-B-3-C & 2 & & & & & & & & \\
\hline 17-A-3-C & 2 & 5093 & 914 & $150-76$ & $64 \times 127$ & 610 & Comp. & $\varnothing 64$ & 305 \\
\hline 18-B-3-T & 2 & 5398 & 914 & $155-76$ & $102 \times 305$ & 762 & Tension & $64 \times 152$ & 305 \\
\hline 20-B-4-C & 2 & 5994 & 1219 & $164-76$ & $102 \times 305$ & 1372 & Comp. & $\varnothing 64$ & 610 \\
\hline 33-B-5-C & 2 & 10058 & 1524 & 261-114 & $102 \times 305$ & 1219 & Comp. & $\varnothing 64$ & 610 \\
\hline 35-B-5-C & 2 & 10566 & 1524 & $270-114$ & $102 \times 305$ & 1219 & Comp. & $\varnothing 64$ & 610 \\
\hline 40-B-5-T & 1 & 12090 & 1524 & 291-114 & $102 \times 305$ & 1219 & Tension & $64 \times 127$ & 305 \\
\hline 29-B-5-C & 1 & 8738 & 1524 & $247-114$ & $64 \times 127$ & 457 & Comp. & $64 \times 152$ & 610 \\
\hline 29-B-5-0 & 1 & 8738 & 1524 & $247-114$ & Without & Without & Without & $64 \times 152$ & 610 \\
\hline 18-B-4-C & 1 & 5398 & 1219 & $155-76$ & $102 \times 305$ & 457 & Comp. & $64 \times 152$ & 610 \\
\hline 18-B-4-T & 2 & 5398 & 1219 & $155-76$ & $102 \times 305$ & 457 & Tension & $64 \times 152$ & 610 \\
\hline
\end{tabular}

(*) $\mathrm{h}_{\text {Total }}$ : Total length of the pole, $\mathrm{h}_{\text {Supported }}$ : Supported length.

(**) AGL: Located Above Ground line, BGL: Located Below Ground line.

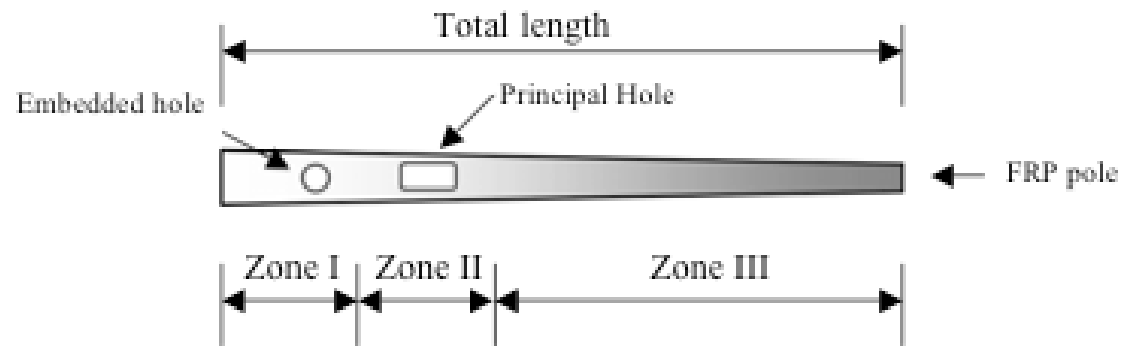

a) Zones of the FRP poles.

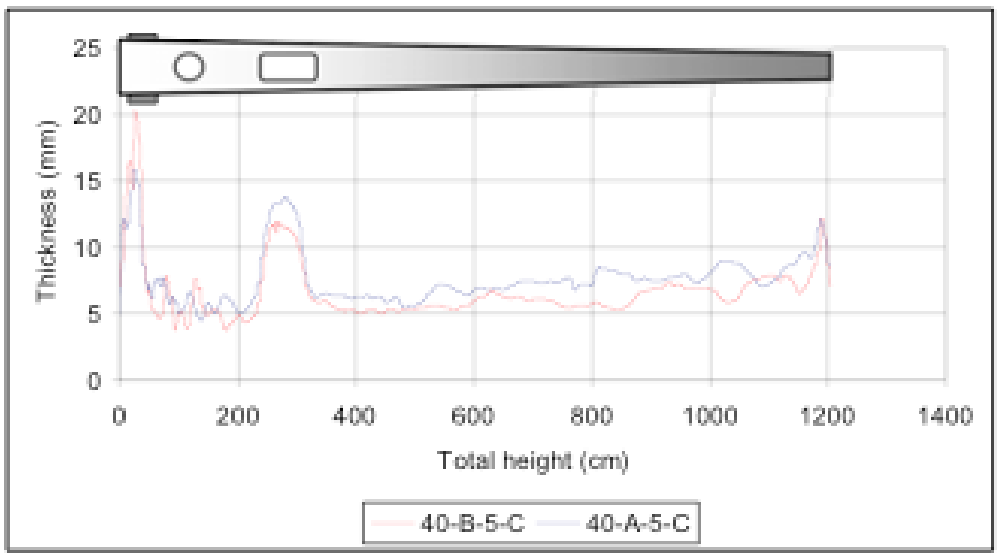

b) Thickness of prototypes 40-B-5-C and 40-A-5-C

Fig. (1). Zones and Thickness of FRP poles. 
parentheses) indicates the test number under the same parameters.

Each type of pole tested in this study is constituted by three zones, where the geometrical and the mechanical properties are different in each zone. The difference of these properties is due to the different number of layers used in each zone and the fiber orientation of each layer (Fig. 1). The stacking sequence as well as the average thickness and length for the three zones of poles are presented in Table $\mathbf{3}$ and Table 4, respectively. The fiber content of each prototype, expressed in mass content $M_{f}$ or in volume ratio $V_{f}$ is presented in Table 4.

It should be mentioned that all the prototypes presented in this study are single segment and were fabricated with extra reinforcing provided around the principal holes except for the prototypes $17-\mathrm{B}-3-\mathrm{C}$ and $17-\mathrm{A}-3-\mathrm{C}$. On the other

Table 3. Stacking Sequence for the Three Zones of the Poles

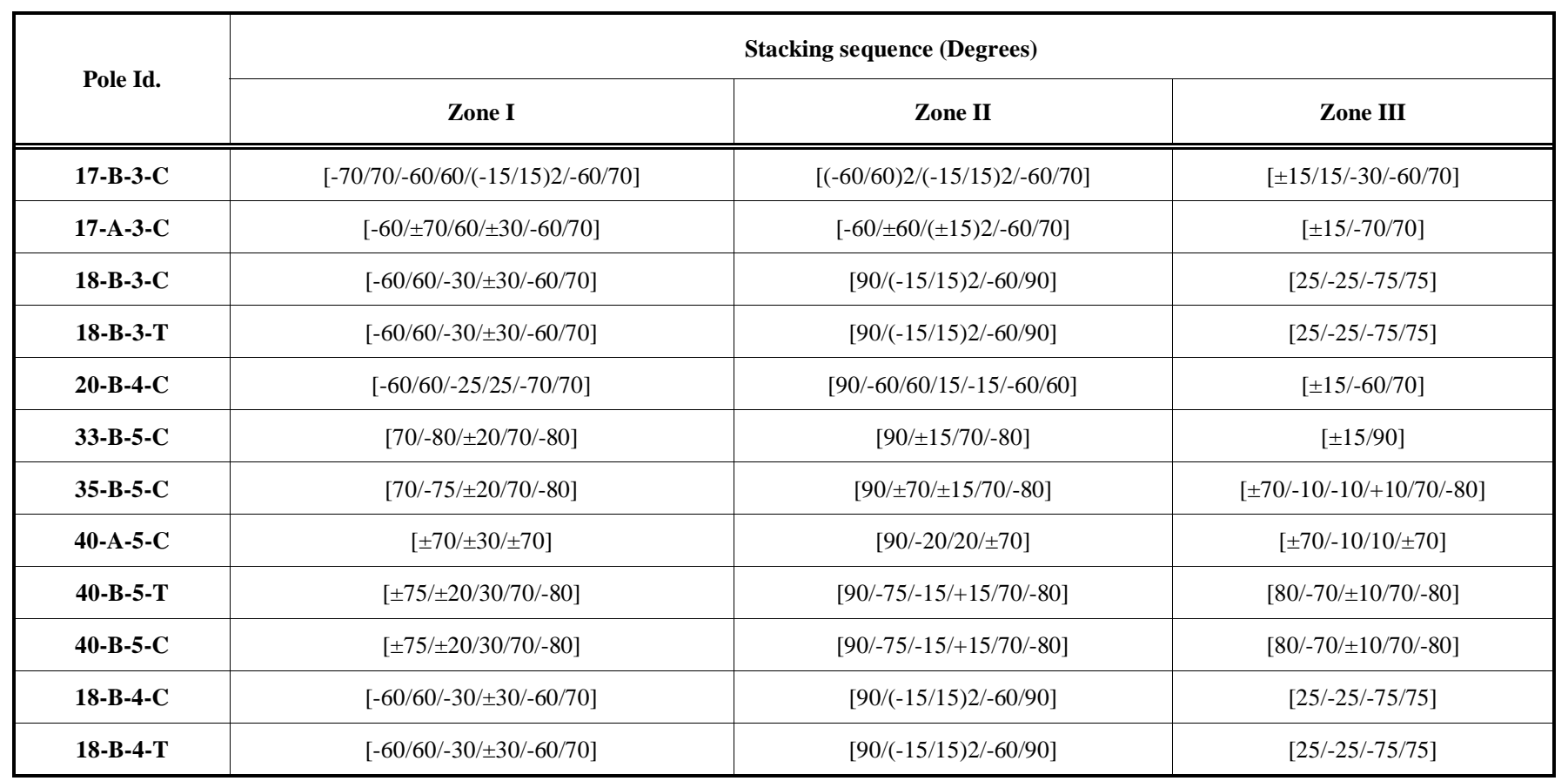

Table 4. Average Thickness and Length for the Three Zones of the Poles

\begin{tabular}{|c|c|c|c|c|c|c|c|c|}
\hline Prototypes & $\mathbf{M}_{\mathrm{f}}(\%)$ & $V_{f}(\%)$ & $\begin{array}{l}\text { Length } \\
(\mathrm{mm})\end{array}$ & $\begin{array}{l}\text { Average thickness } \\
\text { (mm) }\end{array}$ & $\begin{array}{l}\text { Length } \\
(\mathrm{mm})\end{array}$ & Average thickness (mm) & $\begin{array}{c}\text { Length } \\
(\mathbf{m m})\end{array}$ & Average thickness (mm) \\
\hline 17-B-3-C & 67 & 49 & 2133 & 4.78 & 2219 & 4.30 & 740 & 5.18 \\
\hline 17-A-3-C & 67 & 49 & 2133 & 4.78 & 2219 & 4.30 & 740 & 5.18 \\
\hline 18-B-3-T & 69 & 51 & 1220 & 3.27 & 980 & 7.20 & 3198 & 3.04 \\
\hline 20-B-4-C & 68 & 50 & 2000 & 2.81 & 1200 & 6.73 & 2794 & 2.84 \\
\hline 33-B-5-C & 76 & 59 & 2200 & 4.56 & 1000 & 8.35 & 6858 & 5.97 \\
\hline 40-B-5-C & 72 & 55 & 2200 & 5.54 & 1000 & 10.44 & 8890 & 7.73 \\
\hline 18-B-4-C & 69 & 51 & 1220 & 3.27 & 980 & 7.20 & 3198 & 3.04 \\
\hline 18-B-4-T & 69 & 51 & 1220 & 3.27 & 980 & 7.20 & 3198 & 3.04 \\
\hline
\end{tabular}


hand, there was no extra reinforcing provided around the hole located under the ground line. All the holes were cut at the manufacturer site, after the poles were fabricated.

The prototypes (29-B-5-C) and (29-B-5-0) were obtained by cutting out a section of $1829 \mathrm{~mm}$ ( 6 feet) from the bottom end of previously tested prototypes (35-B-5-C). For the prototypes (29-B-5-C) and (29-B-5-0), the dimensions of the

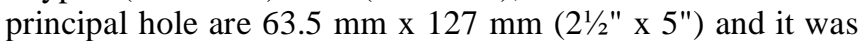
located at $457 \mathrm{~mm}\left(18^{\prime \prime}\right)$ above the ground line. Flexural testing of these both prototypes will highlight the effect of the presence of the hole on the flexural behavior of FRP poles.

\section{Test Setup}

A new test-setup (Fig. 2) was designed and built according to the recommendations of the Standards ASTM D 492301 [11] and ANSI C 136.20-1990 [12] as well as the Proposed California Test 683-1995 [13]. This test-setup consists mainly of three parts: a "ground-line support", a "butt support" and a "lifting jaws". This fixture provides a practical way to test all types of utility poles. The ground-line support or front support is used with wooden saddle to support the pole at ground line and is designed to allow a vertical and/or horizontal translation to anchor the various possible diameters of the poles. The pole butt support or rear support is used with wooden saddle to support the lower end of the pole and is designed to allow longitudinal translation to test various burial lengths of the poles. The lifting jaws constitute the load application point on the pole and consist of two quarters of a metallic tube assembled so as to form two jaws (Fig. 2). After the pole were mounted and leveled on the test fixture, a bridge crane was positioned with its hook centered above the lifting jaws, $305 \mathrm{~mm}$ far from the top of the pole.

\section{Instrumentation}

A $225 \mathrm{KN}$ load-capacity cell was used while the displacement rate of the bridge crane was $12 \mathrm{~mm} / \mathrm{sec}$ (Fig. 2). The deflection of the FRP poles was measured with a draw wire transducer (DWT) at $h_{c} / 4 ; h_{c} / 2$ as well as under the load application point (Fig. 2), where $h_{c}$ is the cantilever length or free length of the pole.

Electrical strain gages were mounted on the two faces (compression and tension) near the ground line support, at $\mathrm{h}_{\mathrm{c}} / 4 ; \mathrm{h}_{\mathrm{c}} / 2 ; 3 / 4 \mathrm{~h}_{\mathrm{c}}$ as well as around the hole. The strain gages were used to monitor the deformations in the longitudinal,

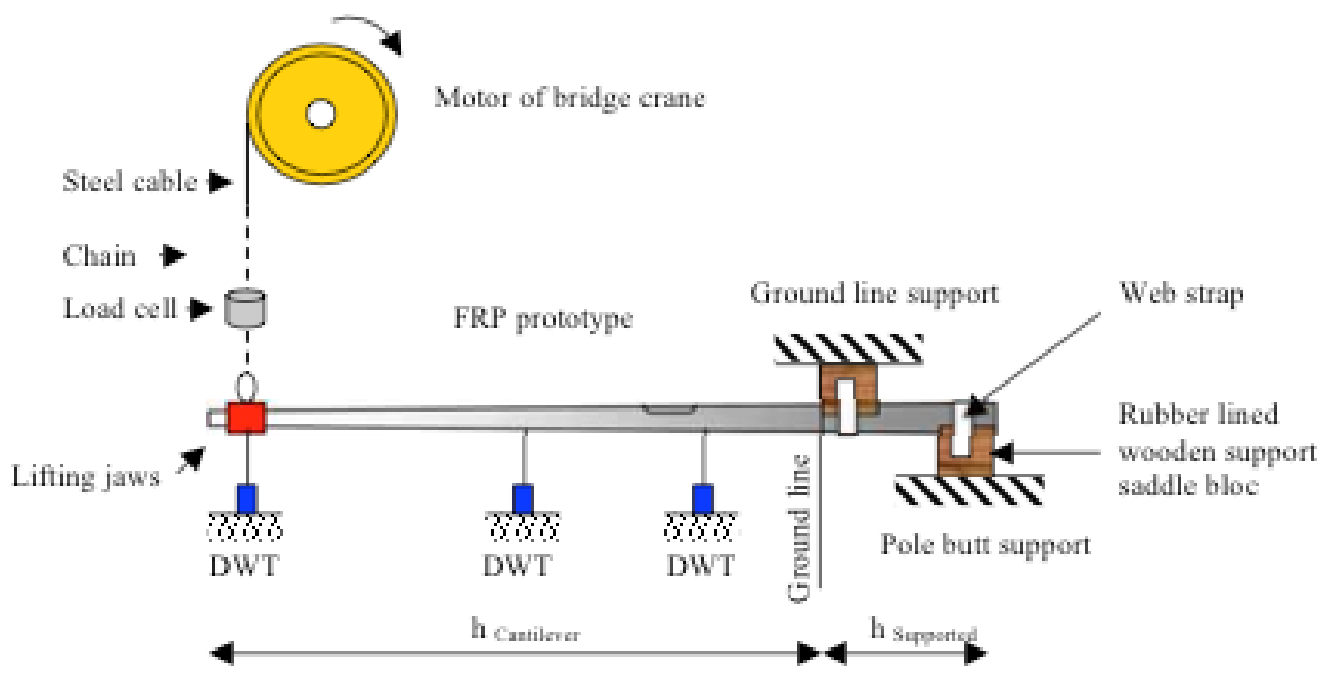

a) Schematic drawing of the full- scale test setup.

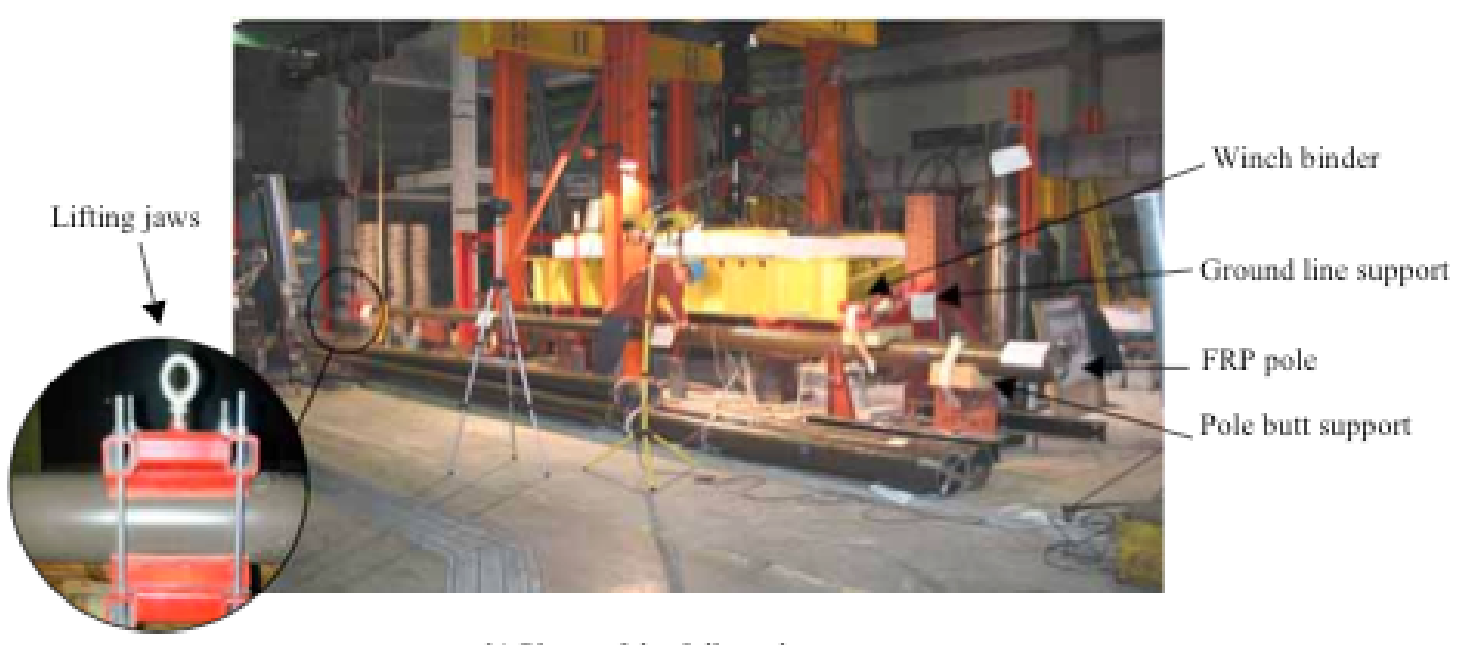

b) Photo of the full- scale test setup.

Fig. (2). Test setup for flexural testing of FRP poles. 
circumferential directions and at 45 degrees from the longitudinal axis of the pole.

Two LVDTs used to measure displacement at the pole base were positioned against either the test fixture or the lower wall of the pole. LVDT \# 1 was centered on the underside of the pole at the ground line. LVDT \# 2 was centered on the topside of the FRP pole above the wooden support on the rear pole butt support. Two other LVDTs were positioned laterally in order to measure the possible ovalisation of the pole near the ground line support.

An automatic data acquisition system was used to collect the load, LVDTs, DWTs and strain gages data.

In this paper, only the results of the load-deflection Behavior are presented. The results of the strain gages reading as well as the LVDT's and the DWTs positioned at $h_{c} / 4 ; h_{c} / 2$ will be presented in future publications.

\section{Ultimate Load-Carrying Capacity and Mode of Failure}

The ultimate load-carrying capacities as well as the maximum deflection at the loading position for the different FRP poles tested in this study are presented in Table $\mathbf{5}$.

The prototypes 1,2, 3 and 4 have the same geometrical characteristics and were tested under the same test configuration and conditions. However, they differ by the type of fi- bers used. Prototypes 1 and 2 are made using type-B fibers where-as prototypes 3 and 4 are made using type-A fibers. Type A fibers has a linear density of $1100 \mathrm{~g} / \mathrm{km}$ compared to $2000 \mathrm{~g} / \mathrm{km}$ (Table 1). The four prototypes were tested with $914 \mathrm{~mm}$ supported length as recommended by ANSI C136.20-1990 Standard [12]. The principal hole was subjected to compression. Failure occurred for the four prototypes at the principal hole (Fig. 3), and characterized by a circumferential compression fracture due to compressivecrushing of the material. This failure was not sudden compared to failure of all the other prototypes. Table $\mathbf{5}$ shows that the average ultimate load of the prototypes 3 and 4 made with type-A fibers is about $20 \%$ higher than the average ultimate load of the prototypes 1 and 2 , made with type-B fibers.

The prototypes 5, 6, 7 and 8 have the same geometrical characteristics and are made of the same type-B fibers. The four poles were tested with $914 \mathrm{~mm}$ supported length. The principal hole of the prototypes 5 and 6 was subjected to compression, where-as it was subjected to tension for the prototypes 7 and 8 . It should be mentioned that the principal hole and the embedded hole of the prototypes 5, 6, 7 and 8 are located on opposite faces of the pole.

Failure for the prototypes 5 and 6 occurred at the hole centered at $305 \mathrm{~mm}$ below the ground line and was charac-

Table 5. Strength, Maximum Top Deflection and Global Flexural Stiffness of Full-Scale GFRP Poles

\begin{tabular}{|c|c|c|c|c|c|c|}
\hline $\begin{array}{c}\text { Proto. } \\
\text { No. }\end{array}$ & Proto. Id. & $\begin{array}{l}\text { Strength } \\
(\mathbf{N})\end{array}$ & $\begin{array}{l}\text { Max. Top de- } \\
\text { flection (mm) }\end{array}$ & $(\mathbf{E} \mathbf{I})\left(\mathbf{N} . \mathbf{m}^{2}\right)$ & Mode of Failure & Location of Failure \\
\hline 1 & 17-B-3-C-(1) & 1484 & 480 & 54127 & Compression & Principal hand hole $610 \mathrm{~mm} \mathrm{AGL}^{*}$ \\
\hline 2 & 17-B-3-C-(2) & 1371 & 445 & 54369 & Compression & Principal hand hole $610 \mathrm{~mm} \mathrm{AGL}^{*}$ \\
\hline 3 & 17-A-3-C-(1) & 1765 & 587 & 54689 & Compression & Principal hand hole $610 \mathrm{~mm} \mathrm{AGL}^{*}$ \\
\hline 4 & 17-A-3-C-(2) & 1670 & 613 & 54057 & Compression & Principal hand hole $610 \mathrm{~mm} \mathrm{AGL}^{*}$ \\
\hline 5 & 18-B-3-C-(1) & 1946 & 1326 & 42685 & Tension & Hole-305 mm BGL ${ }^{*}$ \\
\hline 6 & 18-B-3-C-(2) & 1816 & 1245 & 42313 & Tension & Hole-305 mm BGL ${ }^{*}$ \\
\hline 7 & 18-B-3-T-(1) & 1205 & 842 & 41501 & Compression & Hole-305 mm BGL ${ }^{*}$ \\
\hline 8 & 18-B-3-T-(2) & 1384 & 883 & 42182 & Compression & Hole-305 mm BGL ${ }^{*}$ \\
\hline 9 & $20-B-4-C-(1)$ & 1747 & 1320 & 45375 & Compression and local buckling & Ground Line and $2700 \mathrm{~mm} \mathrm{AGL}^{*}$ \\
\hline 10 & 20-B-4-C-(2) & 2131 & 1564 & 45223 & Compression and local buckling & Ground Line and $2700 \mathrm{~mm} \mathrm{AGL}^{*}$ \\
\hline 11 & 33-B-5-C-(1) & 4458 & 2188 & 392010 & Compression & Principal hand hole $1219 \mathrm{~mm} \mathrm{AGL}^{*}$ \\
\hline 12 & 33-B-5-C-(2) & 4638 & 2196 & 392382 & Compression & Principal hand hole $1219 \mathrm{~mm} \mathrm{AGL}^{*}$ \\
\hline 13 & 35-B-5-C-(1) & 3465 & 1924 & 411142 & Compression & Ground Line \\
\hline 14 & 35-B-5-C-(2) & 3575 & 1930 & 411809 & Compression & Ground Line \\
\hline 15 & 40-A-5-C-(1) & 6160 & 3234 & 687627 & Compression & Ground Line \\
\hline 16 & 40-A-5-C-(2) & 5894 & 2898 & 688383 & Compression & Ground Line \\
\hline 17 & 40-B-5-C-(1) & 4293 & 2626 & 616995 & Compression & Ground Line \\
\hline 18 & 40-B-5-T-(1) & 4445 & 2679 & 616634 & Compression & Ground Line \\
\hline 19 & 29-B-5-C-(1) & 2208 & 818 & 314576 & Compression & Principal hand hole $457 \mathrm{~mm} \mathrm{AGL}{ }^{*}$ \\
\hline 20 & 29-B-5-0-(1) & 6142 & 1987 & 340133 & Compression & Ground Line \\
\hline 21 & 18-B-4-C-(1) & 2360 & 1263 & 36882 & Compression-Shear & Principal hand hole $762 \mathrm{~mm}$ AGL* \\
\hline 22 & 18-B-4-T-(1) & 1945 & 1119 & 36727 & Tension & Principal hand hole $762 \mathrm{~mm}$ AGL $^{*}$ \\
\hline 23 & 18-B-4-T-(2) & 1935 & 1059 & 36864 & Tension & Principal hand hole $762 \mathrm{~mm}$ AGL \\
\hline
\end{tabular}

(*) AGL: Above Ground line, BGL: Below Ground line. 


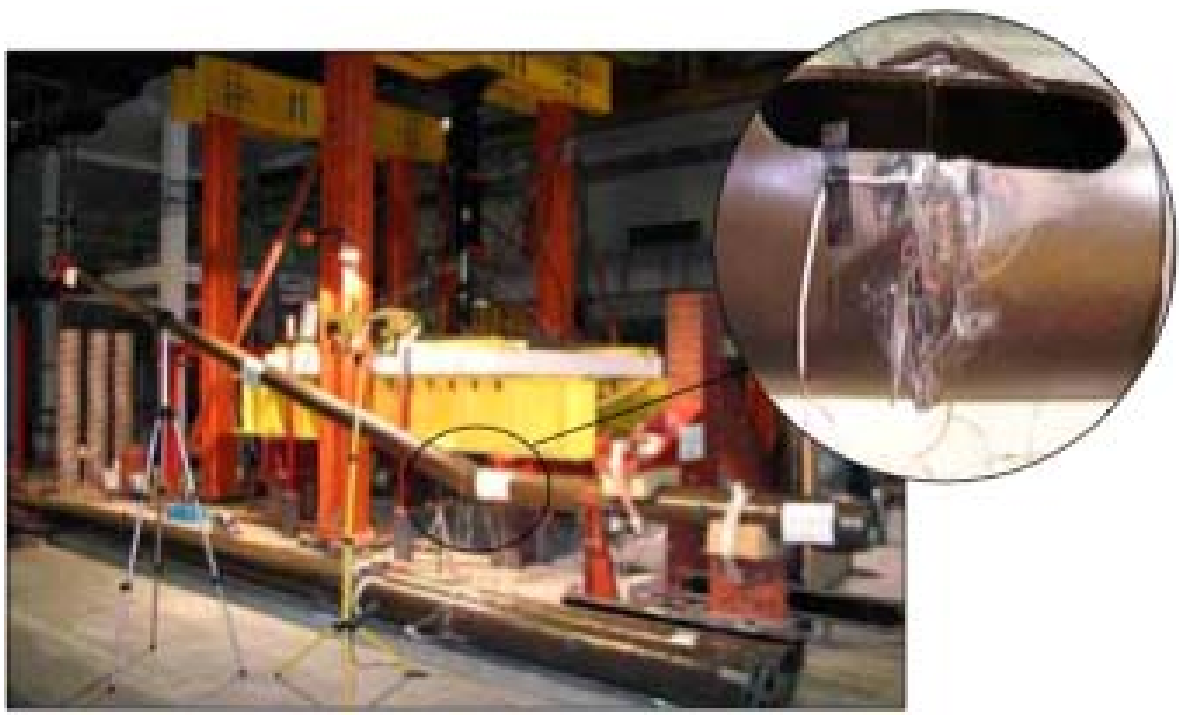

Fig. (3). Circumferential compression fracture for the poles. 17-A-3-C; 17-B-3-C; 29-B-5-C-(1) and 33-B-5-C.

terized by tension failure (Fig. 4). Failure for the prototypes 7 and 8 occurred also at the same hole, $305 \mathrm{~mm}$ below the ground line and was characterized by compression failure. It seems that the stress state is critical at this location for the 18 feet poles and that the design configuration (thickness, stacking sequence) is not adequate for zone I of the 18 feet poles.

Table 5 shows that the average ultimate load of the prototypes 5 and 6 (the underground hole subjected to tension) is about $45 \%$ higher than the average ultimate load of the prototypes 7 and 8 (the underground hole subjected to compression). This is mainly attributed to local buckling due to concentrated stresses around the underground hole.

No observed signs of failure at any other part of the prototypes 6,7 and 8 , such as cracking or crushing of the resin and fibers, appeared during the tests. The prototypes $6 ; 7$ and 8 were re-tested (poles 21; 22 and 23, respectively) with $1219 \mathrm{~mm}(4 \mathrm{ft})$ supported length instead of $914 \mathrm{~mm}(3 \mathrm{ft})$ supported length. All the other test-conditions and configurations were kept the same.

The prototypes 9 and 10 were tested with $1219 \mathrm{~mm}$ (5 feet) supported length, where the principal hole was sub- jected to compression. A brittle failure occurred at the first support location (ground-line support) and was characterized by combined flexion-compression failure. This failure was followed by a local buckling failure at $2740 \mathrm{~mm}$ far from the ground line support; the average ultimate load of these two prototypes was $1939 \pm 272$ N, (Fig. 5).

The prototypes 11 to 14 are made of type-B fibers and were tested in the same test configuration with $1520 \mathrm{~mm}$ (5 feet) supported length. The principal hole was subjected to compression. For the poles 11 and 12 , a brittle failure occurred at the principal hole and was characterized by a circumferential compression failure (Fig. 3). The average ultimate load of the poles 11 and 12 is $4548 \pm 127 \mathrm{~N}$. For the poles 13 and 14, a brittle failure occurred near the ground line support and was characterized by a combined flexioncompression failure (Fig. 6). The average ultimate load of the poles 13 and 14 is $3520 \pm 78 \mathrm{~N}$.

The prototypes 15,16 have the same geometrical characteristics as the prototypes 17 and 18 . However, they differ by the type of fibers used. The prototypes 15 and 16 are made using the type-A fibers, while the prototypes 17 and 18 are made using the type-B fibers. The prototypes 15 and 16 were

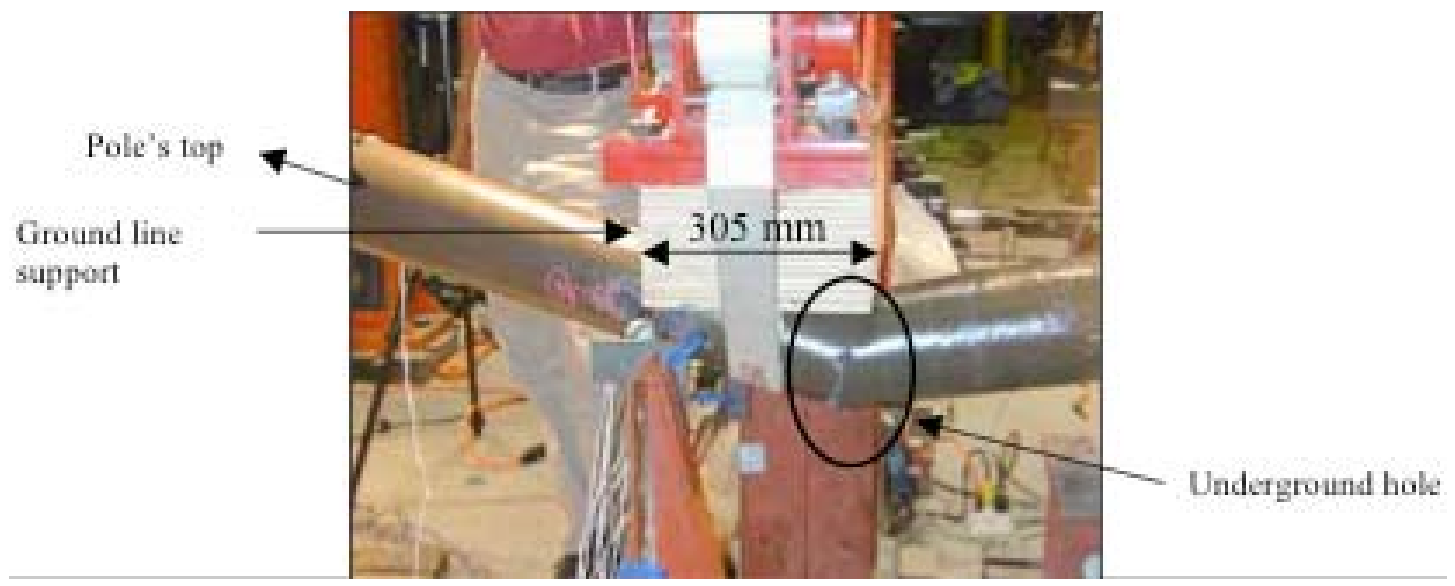

Fig. (4). Tension fracture at the underground hole for the 18-B-3-C poles. 


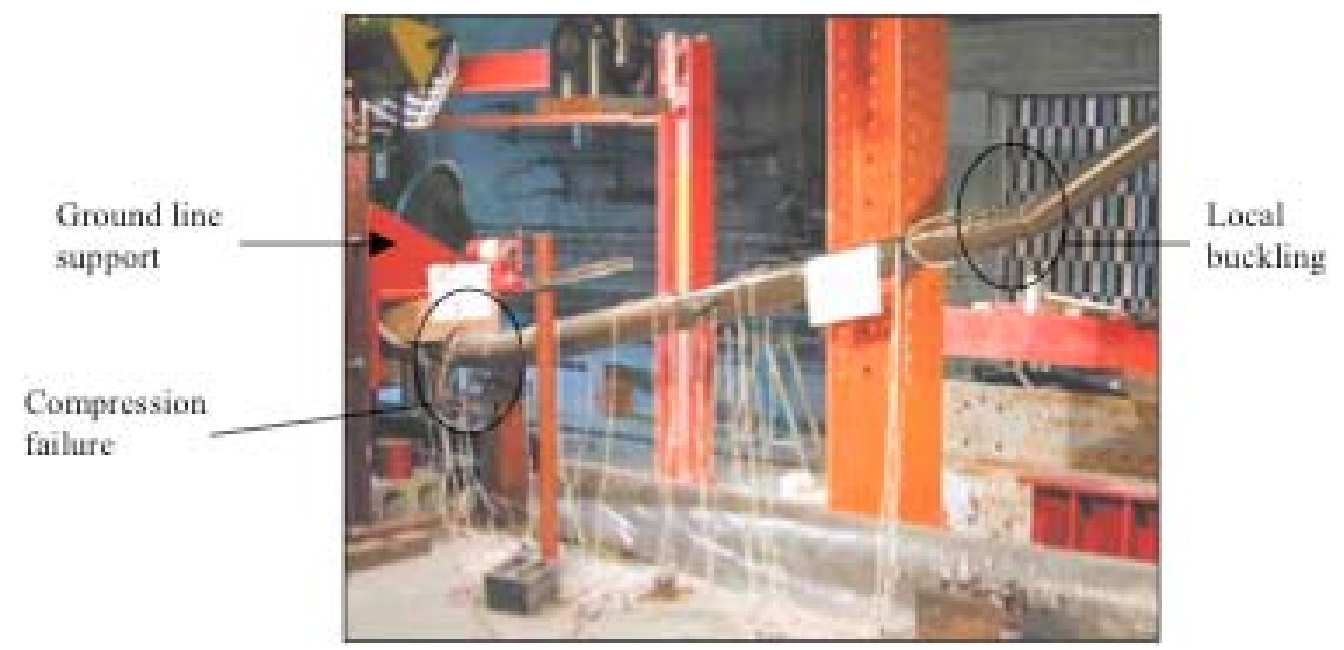

Fig. (5). Compression failure near the ground line followed by local buckling $2740 \mathrm{~mm}$ far from the ground line, for the 20-B-4-C poles.

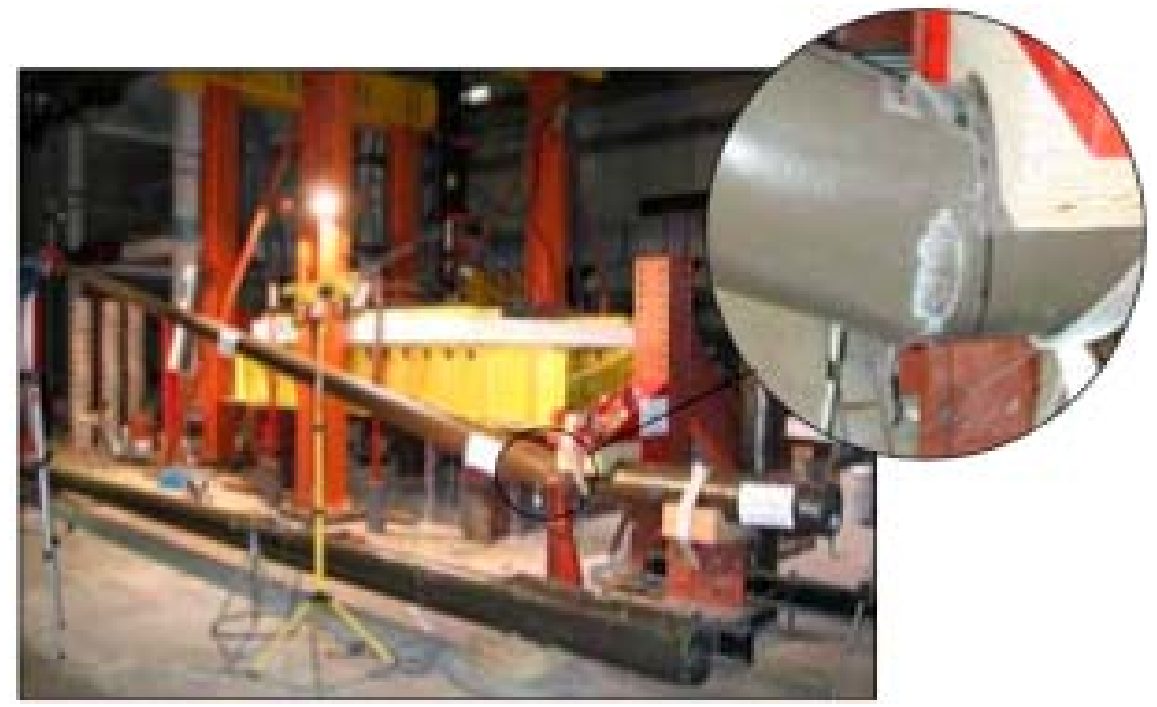

Fig. (6). Compression fracture due to crushing of the material for the poles 29-B-5-0-(1); 35-A-5-C ; 40-A-5-C; 40-B-5-C and 40-B-5-T.

tested with $1520 \mathrm{~mm}$ (5 feet) supported length as recommended by ANSI C136.20-1990 Standard [12] and their principal hole was subjected to compression. A brittle failure occurred at the ground line support and was characterized by flexion-compression failure (Fig. 6). The same failure mode is observed for the prototypes 17 and 18. The average ultimate load of the poles 15 and 16 is $6027 \pm 188 \mathrm{~N}$ which is $38 \%$ higher than the average ultimate load of the poles 17 and $18(4369 \pm 107 \mathrm{~N})$.

The principal hole of the prototypes 17 was subjected to compression while the principal hole of the prototypes 18 was subjected to tension. Table 5 shows that the difference between the ultimate load of the two poles is about $3.5 \%$, it means that the ultimate load of this type of poles is not affected by the hole position since the failure didn't occur at the hole and occurred elsewhere. This is probably due to the presence of high number of circumferential layers (about 60 $\%$ at $90^{\circ}$ and $10 \%$ at $\pm 70^{\circ}$ ) of this zone which confers to it a high resistance against a local buckling [10]. It should be noted that in the case of prototypes 17 and 18 , the width of the principal hole accounts for $13 \%$ of the pole's perimeter while it accounts for $25 \%$ of the pole's perimeter in the case of prototypes 5, 6, 7 and 8. Also, the high thickness compared to the other zones confers to this zone a higher moment of inertia.

The prototypes 19 and 20 have the same geometrical characteristics and are made of the same type-B fibers; they were tested with $1520 \mathrm{~mm}$ supported length. The prototype 19 has a principal hole (dimensions $63.5 \mathrm{~mm}$ x $127 \mathrm{~mm} \mathrm{(2 \frac {1 } { 2 } "}$ x 5") ) located at $457 \mathrm{~mm}$ (18") above ground line and was subjected to compression during testing; while the prototype 20 was tested without any hole above ground line. Failure occurred for the prototype 19 at the principal hole and was characterized by a circumferential compression failure (Fig. 3 ). For the prototype 20, failure occurred at the ground line support and was characterized by a brittle flexioncompression failure (Fig. 6).

Table 5 shows that the ultimate load is equal to $2208 \mathrm{~N}$ for the prototype 19 (with a hole above ground line), compared to $6142 \mathrm{~N}$ for the prototype 20 (without hole). This is a 


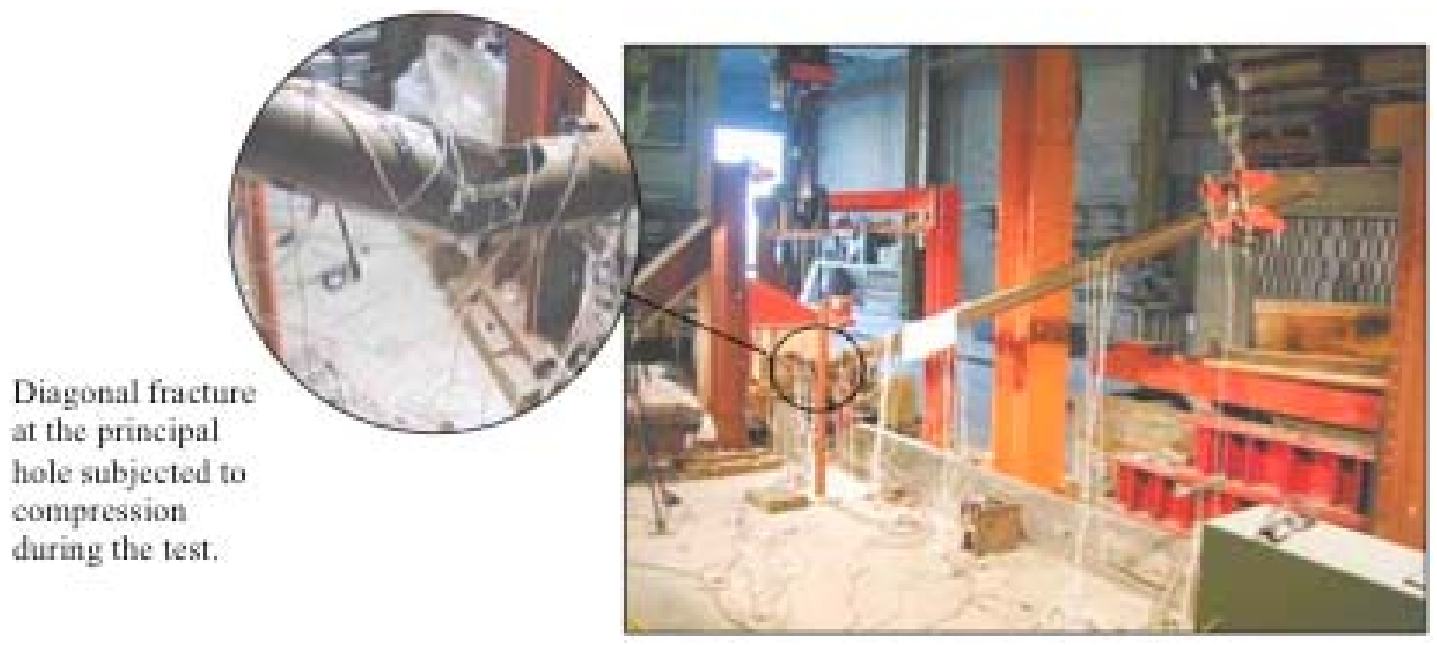

Fig. (7). Diagonal compression fracture for the pole 18-B-4-C-(1).

significant reduction of the ultimate-load carrying capacity due to the presence of the principal hole.

The prototypes $21 ; 22$ and 23 have the same geometrical characteristics and are made of the same type-B fibers; the four poles were tested with $1219 \mathrm{~mm}$ supported length. The principal hole of the prototype 21 was subjected to compression and the principal hole of the prototypes 22 and 23 was subjected to tension. Prototypes 21;22 and 23 failed all at the principal hole located above ground line. For the prototype 21; a brittle failure occurred at the principal hole and was characterized by diagonal-compression (shear) failure (Fig. 7). For the prototypes 22 and 23; this failure was characterized by a diagonal-tension (shear) failure at the principal hole. The shear mode of failure for these prototypes is mainly due to twisting around the principal hole.

Table 5 shows that the ultimate load of the prototype 21 $(2360 \mathrm{~N})$ tested with a hole subjected to compression is about $22 \%$ higher than the average ultimate load of the prototypes 22 and $23(1940 \mathrm{~N} \pm 7 \mathrm{~N})$ tested with a hole subjected to tension.

\section{Load-Deflection Behavior}

Typical load-deflection curves obtained from bending testing for FRP poles are shown in Fig. 8. Some load-

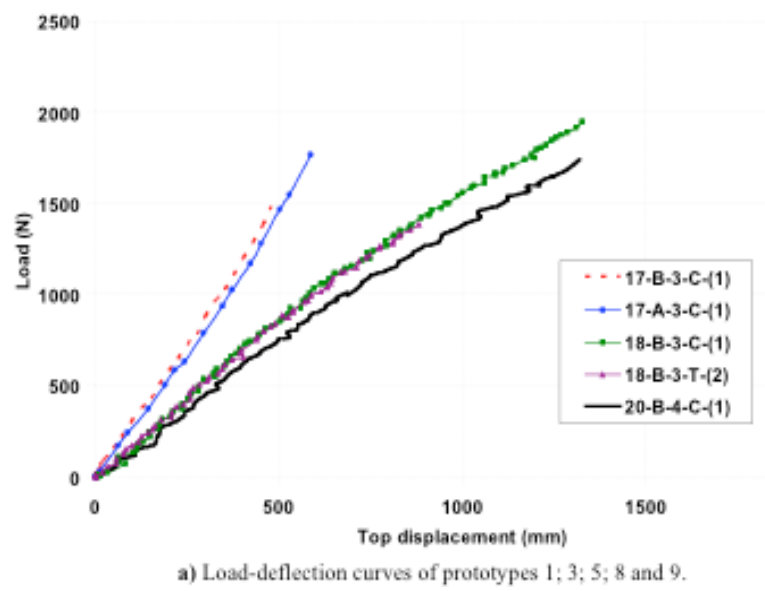

Fig. (8). Typical Load-deflection curves. deflection curves of the tested poles show a small convex curvature before reaching the ultimate load, which indicates a small reduction in flexural stiffness. This is probably due to the fact that when a GFRP pole is subjected to bending moment, the stresses resulting from the applied moment tend to flatten or ovalize the cross section [14]. However, in order to determine the trend of the pole's behavior under lateral loading, fitting curves were plotted for each experimental load-deflection graph.

The coefficient of regressing $\left(\mathrm{R}^{2}\right)$ was determined for each prototype using polynomial trend curves of different degrees. The coefficient of regressing $\left(R^{2}\right)$ indicates the rate of correspondence between the trend curve and the experimental curve. The values of $\left(\mathrm{R}^{2}\right)$ indicate that the polynomials of degree 2 or 3 represent the experimental curves accurately, however, the linear straight line represents also accurately the experimental curves, which confirm that the loaddeflection behavior of the GFRP poles under lateral loading can be considered linear up to failure [4].

Since each type of the FRP poles is constituted by three zones, where the geometrical and the mechanical properties are different in each zone, thus, a global flexural stiffness $(E I)$ is evaluated based on the experimental load-top deflection curves as follow (Equations 1.a and 1.b):

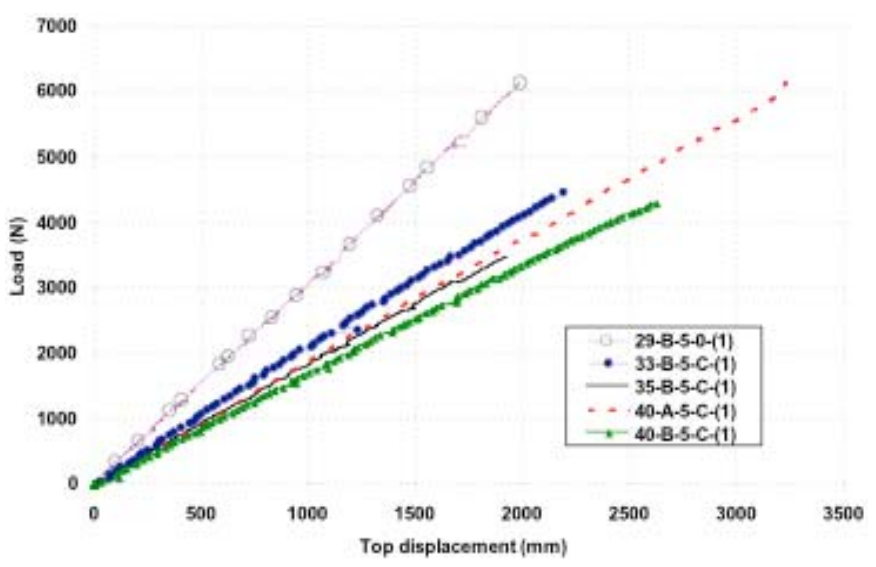

b) Load-deflection curves of prototypes 11; 13; 15:17 and 20 . 
$\Delta=\frac{F\left(h_{c}-a\right)^{3}}{3 E I}=\frac{1}{A} F \ldots$

Which can be written as:

$$
\frac{1}{A}=\frac{\left(h_{c}-a\right)^{3}}{3 E I}, \text { and } A=\frac{3 E I}{\left(h_{c}-a\right)^{3}}
$$

And the global flexural stiffness $E I$ is defined as:

$$
E I=\frac{1}{3} A\left(h_{c}-a\right)^{3} \cdots
$$

Where $(\Delta)$ is the experimental deflection at the loading position located at a distance $a(\mathrm{~mm})$ from the top of the pole, $F$ is the applied load $(\mathrm{N}) ; A(\mathrm{~N} / \mathrm{mm})$ is the slope of the experimental load- deflection curve; $h_{c}$ is the cantilever length or free length of the pole. The global flexural stiffness EI for all the tested prototypes is presented in Table 5.

The results of Table $\mathbf{5}$ show that the global flexural stiffness of the prototypes 3 and 4 made with the type-A fibers is higher than that of the prototypes 1 and 2 made using the type-B fibers. This difference is more evident in the case of the poles $15 ; 16 ; 17$ and 18 , where the poles 15 and 16 are made using the type-A fibers and the poles $17 ; 18$ are made using the type-B fibers.

This is due to the low linear density (Table 1) of the typeA fibers which confers to them a better capacity of resin absorption at the wetting phase of the filament winding process. The resin being better impregnated makes it able to create bonds between fibers and reduce the rate of voids thus giving better woven and more resistant laminates. These results show that the use of fibers with low linear density leads to better mechanical performances.

The global flexural stiffness of the pole 19 tested with a hole above the ground line accounts for $90 \%$ of the global flexural stiffness of the pole 20 tested without any hole above the ground-line.

The global flexural stiffness of the poles 21 and the poles $22 ; 23$ shows that the hole positioning (under compression or tension) doesn't affect the flexural stiffness of the poles, this is more evident in the case of the prototypes $17 ; 18$.

The prototypes 15 and 16 present the highest values of global flexural stiffness; this is due to their important geometrical dimensions compared to the other poles and the use of the type-A fibers.

\section{THEORETICAL PREDICTION OF FRP POLES DE- FLECTION}

\section{Theoretical Model}

It should be remembered that each type of the FRP poles tested in this study is constituted by three zones where the geometrical and the mechanical properties are different in each zone (see Fig. 1-appendix). Thus, based on the method of beam theory [15], the lateral deflection $y_{3}\left(l_{3}\right)$ (Fig. 1Appendix) at the loading position located at a distance $a$ from the top of the pole is predicted using Equations (1.a to 1.c - Appendix), where $F$ is the applied load, $M(x)$ is the bending moment expression (Equation 2 - appendix), $E_{1} ; E_{2}$; $E_{3}$ are the Young's modulus in the longitudinal direction of the lamina which corresponds to the zones $1 ; 2 ; 3$ respectively, $I_{1}(x) ; I_{2}(x) ; I_{3}(x)$ are the expressions of the moment of inertia of the zones $1 ; 2 ; 3$ respectively (Equations 3.a to 3.c - appendix)., $l_{1} ; l_{2} ; l_{3}$ are the cumulated lengths of the zones $1 ; 2 ; 3$ respectively, $t_{1} ; t_{2} ; t_{3}$ are the average wall thickness of the zone $1 ; 2 ; 3$ respectively, $r(x)$ is the expression of the internal radius over the total length of the pole (Equation 4 - appendix), $r_{b}$ and $r_{t}$ are the internal radius at the bottom and the top of the pole, respectively, $h_{T}$ and $h_{c}$ are the total length and the cantilever (or free) length of the pole, respectively, $y_{j}^{\prime \prime}(x) ; y_{j}{ }^{\prime}(x) ; y_{j}(x)$ are the curvature function, the rotation function and the displacement function in the zone $j$, respectively, where $j$ is the number of the zone considered $(j=1 ; 2 ; 3), c_{j}$ and $d_{j}$ are the constants of integrations and are determined by the boundary conditions (Equations 5.a to 5.c - appendix). The maximum lateral deflection at the loading position $y_{3}\left(l_{3}\right)_{\max }$ is obtained for the ultimate load $F_{u}$.

\section{Orthotropic Laminate Mechanical Properties}

Glass fiber reinforced polymer is used as the construction material for the poles investigated. The lamina properties were derived from the material properties of the E-glass fibers and the resin. These properties are used to derive the effective modulus of the composite material based on micromechanical models [14] and the rule of mixture [16] is used to evaluate the modulus of elasticity in the fiber direction $\left(E_{l}\right)$; the modulus of elasticity in the transverse direction $\left(E_{t}\right)$; the shear modulus $\left(G_{l t}\right)$ and the Poisson's ratio $\left(v_{l t}\right)$ as follows:

$$
\begin{aligned}
& E_{l}=E_{f} V_{f}+E_{m} V_{m} \ldots \\
& E_{t}=E_{m}\left[\frac{1}{\left(1-V_{f}\right)+\left(\frac{E_{m}}{E_{f t}} V_{f}\right)}\right] \cdots \\
& G_{l t}=G_{m}\left[\frac{1}{\left(1-V_{f}\right)+\left(\frac{G_{m}}{G_{f l t}} V_{f}\right)}\right] \cdots \\
& v_{l t}=v_{f} V_{f}+v_{m} V_{m} \ldots
\end{aligned}
$$

Where $V_{f}$ and $V_{m}$ are the fiber and the matrix volume ratio, respectively; $E_{f}$ and $E_{m}$ are the fiber and the matrix modulus of elasticity, respectively; $v_{f}$ and $v_{m}$ are the fiber and the matrix Poisson's ratios, respectively; $E_{f t}$ is the fiber longitudinal modulus of elasticity in the transverse direction of the fiber, $G_{f l t}$ and $G_{m}$ are the fiber and the matrix shear modulus respectively. Equations (2) to (5) are used to determine the effective material properties for the composite lamina. The fiber volume ratio, $V_{f}$ and the matrix volume ratio, $V_{m}$ were calculated based on the fiber and matrix weightcontents, which were obtained experimentally.

The following relationships (Equation 6) to (Equation 8) are used to determine the modulus of elasticity $E_{j}$ in the longitudinal direction of the pole for the lamina which constitutes the zone $(j),(j=1 ; 2 ; 3)$. [16]: 
$E_{j}=\sum_{i=1}^{n}\left\{\left(P_{i}\right) E_{x i}\right\} \quad j=1 ; 2 ; 3 \ldots$

And

$$
E_{x i}=\frac{1}{\frac{\cos ^{4} \theta_{i}}{E_{l}}+\frac{\sin ^{4} \theta_{i}}{E_{t}}+\cos ^{2} \theta_{i} \sin ^{2} \theta_{i}\left(\frac{1}{G_{l t}}-2 \frac{v_{t l}}{E_{t}}\right)}
$$

And $\frac{v_{t l}}{E_{t}}=\frac{v_{l t}}{E_{l}} \cdots$

Where $E_{x i}$ is the Young's modulus in the longitudinal direction of the $i^{\text {th }}$ layer, $(n)$ is the total number of layers in the zone $(j), v_{t l}$ and $v_{l t}$ are the Poisson's ratios, $\theta_{i}$ is the fiber angle of the $i^{\text {th }}$ layer evaluated experimentally by a pyrolysis test, $P_{i}$ is the percentage representing the $i^{\text {th }}$ layer of the laminate constituting a given zone. The percentage representing each layer was evaluated by determining the thickness of each layer using scanning electron microscope.

\section{COMPARISON BETWEEN EXPERIMENTAL AND THEORETICAL RESULTS}

Typical load-deflection curves obtained from both the experimental and the theoretical results are shown in Fig. 9.
The theoretical curve $y_{3}(x)$ is a linear function in $F$ (Equations. 1.c - appendix and 2-appendix), thus; for the boundary conditions at $x=l_{3}$ are:

$\left\{\begin{array}{l}F=0: y_{3}\left(l_{3}\right)=0 \\ F=F_{u}: y_{3}\left(l_{3}\right)=y_{3}\left(l_{3}\right)_{\max }\end{array}\right.$

Where $F$ is the applied load, $F_{u}$ is the ultimate applied load, $y_{3}\left(l_{3}\right)$ is the lateral deflection at the loading position.

The maximum pole top deflection at the loading position obtained from both experimental and theoretical results are presented in Table $\mathbf{6}$. Table $\mathbf{6}$ shows a comparison between the experimental and the predicted pole top deflection. The average ratio between the experimental and the predicted pole top deflection was approximately 1.00 with a standard deviation of $8 \%$.

Table 6 presents a comparison between the experimental and the theoretical flexural stiffness $(E I)$ evaluated respectively from the experimental and the theoretical loaddeflection curves. Table $\mathbf{6}$ shows that the average ratio between the experimental and the theoretical flexural stiffness was approximately 1.05 with a standard deviation of $11 \%$.

It can be concluded that the theoretical model presented herein, is in good agreement with the experimental results.

Table 6. Comparison Between Experimental and Theoretical Maximum Top Deflection and the Flexural Stiffness

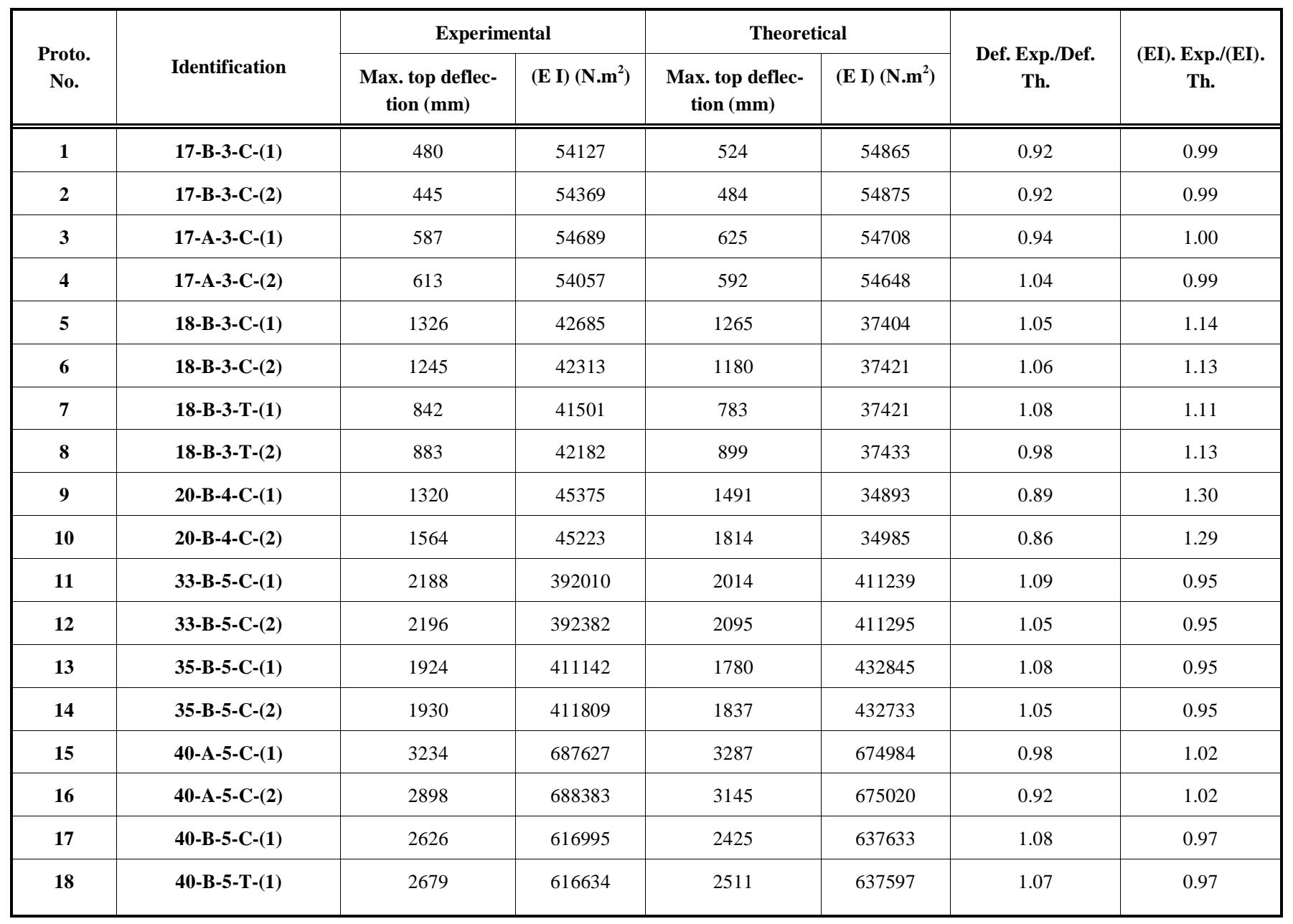



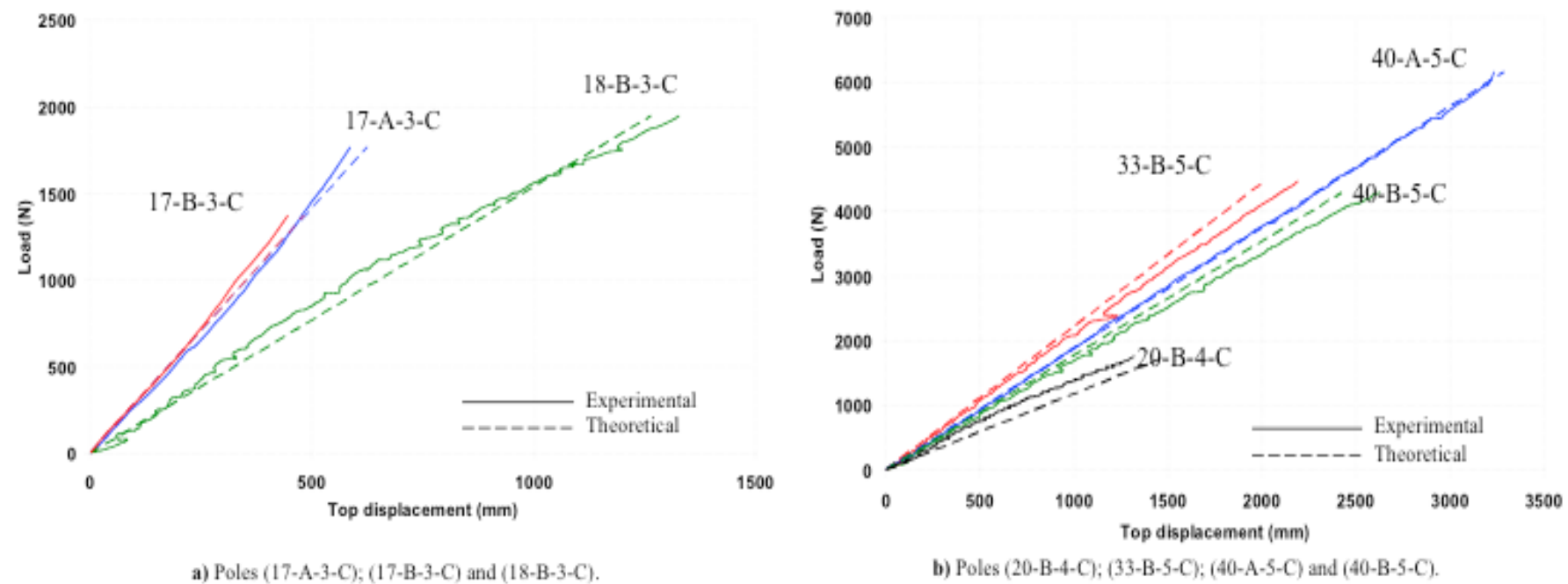

Fig. (9). Typical comparison between experimental and theoretical load-deflection relationship.

\section{CONCLUSIONS}

In this study, the full-scale flexural Behavior of Fiber Reinforced Polymer (FRP) tapered poles manufactured by the filament winding process is investigated experimentally and theoretically. A new test-setup was designed and built according to the recommendations described in ASTM and ANSI standards.

Different types of FRP poles, having different geometrical properties and made of two different types of glass fibers were subjected to full scale flexural static testing. Each type of the poles tested in this study is constituted by three zones where the geometrical and the mechanical properties are different in each zone. The difference of these properties is due to the different number of layers used in each zone and the fiber orientation of each layer. Pyrolysis tests and scanning electron microscope analysis were used in this investigation to determine the fiber and the matrix volume ratio as well the stacking sequences of the different pole's zones.

Also, the effect of the presence and positioning (under compression or tension) of the hole as well as the type of fibers, on the flexural behavior of FRP poles (in terms of load carrying capacity, load-deflection stiffness and maximum top deflection) were evaluated and quantified.

The following conclusions can be drawn:

1. The experimental results of the current investigation show that the load-deflection behavior of GFRP poles under lateral loading is linear up to failure.

2. Flexion-compression and flexion tension failures were observed for the most tested prototypes.

3. The theoretical linear model, based on the beam theory, predicts with good accuracy the experimental load-deflection behavior as well as the maximum top deflections.

4. The use of low linear density-glass fibers improves the mechanical performance of GFRP poles in terms of flexural stiffness and ultimate load carrying capacity.

5. The presence of a hole above ground line without additional fiberglass reinforcement decreases the strength and the flexural stiffness; and constitutes a critical location for bending failure of GFRP poles.

6. When failure occurred at a hole constituted mainly by longitudinal layers (Prototypes 4; 5; 6 and 7); the average strengths obtained when this hole was subjected to tension is about $45 \%$ higher than those obtained when it was subjected to compression.

7. In the case where failure occurred at a hole constituted mainly by circumferential layers (Prototypes $21 ; 22$ and 23); the strength obtained when this hole was subjected to compression is about $22 \%$ higher than that obtained when it was subjected to tension.

8. It is noted that the flexural stiffness is not affected by the hole positioning.

\section{APPENDIX}

$0 \leq x \leq l_{1}$

$\left\{\begin{array}{l}y_{1}{ }^{\prime \prime}(x)=\frac{d^{2} y_{1}}{d x^{2}}=\frac{-M(x)}{E_{1} I_{1}(x)} \\ y_{1}^{\prime}(x)=\frac{d y_{1}}{d x}=\int \frac{-M(x)}{E_{1} I_{1}(x)} d x+c_{1} \\ y_{1}(x)=\iint\left[\frac{-M(x)}{E_{1} I_{1}(x)} d x\right] d x+c_{1} x+d_{1}\end{array}\right.$

$l_{1} \leq x \leq l_{2}$

$\left\{\begin{array}{l}y_{2}^{\prime \prime}(x)=\frac{d^{2} y_{2}}{d x^{2}}=\frac{-M(x)}{E_{2} I_{2}(x)} \\ y_{2}{ }^{\prime}(x)=\frac{d y_{2}}{d x}=\int \frac{-M(x)}{E_{2} I_{2}(x)} d x+c_{2} \\ y_{2}(x)=\iint\left[\frac{-M(x)}{E_{2} I_{2}(x)} d x\right] d x+c_{2} x+d_{2}\end{array}\right.$ 


$$
\begin{aligned}
& l_{2} \leq x \leq l_{3} \\
& \left\{y_{3}{ }^{\prime}(x)=\frac{d y_{3}}{d x}=\int \frac{-M(x)}{E_{3} I_{3}(x)} d x+c_{3}\right. \\
& y_{3}(x)=\iint\left[\frac{-M(x)}{E_{3} I_{3}(x)} d x\right] d x+c_{3} x+d_{3} \\
& \text { Where: } \\
& M(x)=F\left(x-l_{3}\right) \quad \ldots \\
& I_{1}(x)=\frac{\pi}{4}\left\{\left(r(x)+t_{1}\right)^{4}-r(x)^{4}\right\} \cdots \\
& I_{2}(x)=\frac{\pi}{4}\left\{\left(r(x)+t_{2}\right)^{4}-r(x)^{4}\right\} \cdots \\
& I_{3}(x)=\frac{\pi}{4}\left\{\left(r(x)+t_{3}\right)^{4}-r(x)^{4}\right\} \ldots \\
& r(x)=\left(h_{c}-x\right) \frac{\left(r_{b}-r_{t}\right)}{h_{T}}+r_{t} \cdots
\end{aligned}
$$$$
y_{3}^{\prime \prime}(x)=\frac{d^{2} y_{3}}{d x^{2}}=\frac{-M(x)}{E_{3} I_{3}(x)}
$$$$
\begin{aligned}
& y_{3}^{\prime \prime}(x)=\frac{d^{2}}{d x^{2}}=\frac{-M(x)}{E_{3} I_{3}(x)} \\
& y_{3}^{\prime}(x)=\frac{d y_{3}}{d x}=\int \frac{-M(x)}{E} d x+c_{3}
\end{aligned}
$$

The constants of integrations are determined by the following boundary conditions (Equations 5.a to 5.c):

$$
\begin{aligned}
& 0 \leq x \leq l_{1} \\
& y_{1}^{\prime}(0)=0 \quad \text { and } \quad y_{1}(0)=0 \\
& l_{1} \leq x \leq l_{2} \\
& y_{1}{ }^{\prime}\left(l_{1}\right)=y_{2}{ }^{\prime}\left(l_{1}\right) \quad \text { and } \quad y_{1}\left(l_{1}\right)=y_{2}\left(l_{1}\right)^{\cdots} \\
& l_{2} \leq x \leq l_{3} \\
& y_{2}{ }^{\prime}\left(l_{2}\right)=y_{3}{ }^{\prime}\left(l_{2}\right) \quad \text { and } \quad y_{2}\left(l_{2}\right)=y_{3}\left(l_{2}\right)^{\cdots}
\end{aligned}
$$

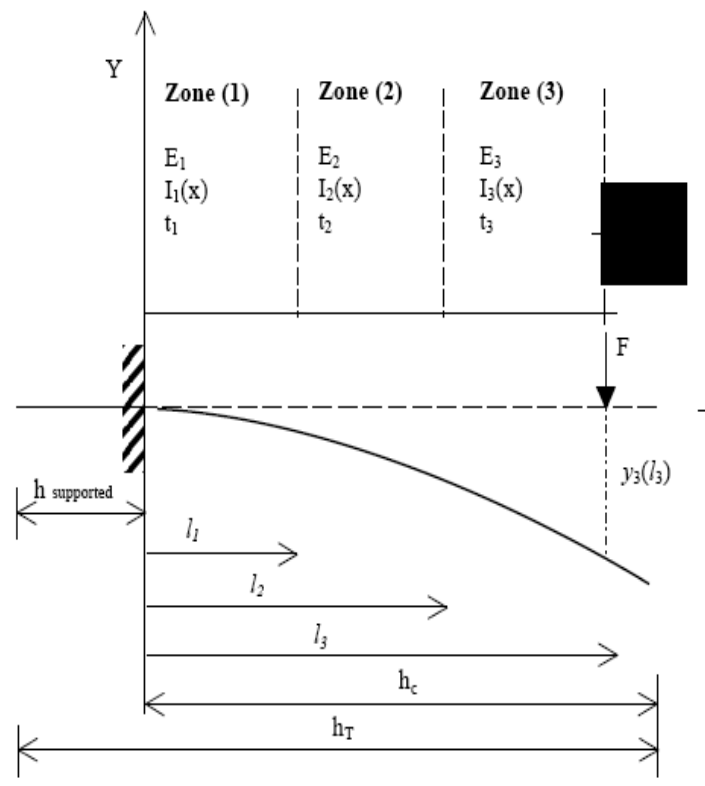

Fig. (1) appendix. FRP pole as cantilever beam.

\section{LIST OF SYMBOLS}

a

A

$\mathrm{c}_{\mathrm{j}}$

$d_{j}$

$\mathrm{E}_{\mathrm{f}} ; \mathrm{E}_{\mathrm{m}}$

$\mathrm{E}_{\mathrm{ft}}$

$\mathrm{E}_{1}$

$\mathrm{E}_{\mathrm{t}}$

$\mathrm{E}_{\mathrm{xi}}$

$E_{j}$

$\mathrm{E}_{1} ; \mathrm{E}_{2} ; \mathrm{E}_{3}$

EI

F

$\mathrm{F}_{\mathrm{u}}$

$\mathrm{G}_{\mathrm{flt}} ; \mathrm{G}_{\mathrm{m}}$

$\mathrm{G}_{\mathrm{lt}}$

$\mathrm{h}_{\mathrm{T}}$

$\mathrm{h}_{\mathrm{c}}$

$\mathrm{h}_{\text {supported }}$

$\mathrm{I}_{1}(\mathrm{x}) ; \mathrm{I}_{2}(\mathrm{x}) ; \quad$ Expressions of moment of inertia of the zone $\mathrm{I}_{3}(\mathrm{x})$

$\mathrm{j}$

$1_{1} ; 1_{2} ; 1_{3}$

$\mathrm{M}(\mathrm{x})$

$\mathrm{n}$

$\mathrm{r}(\mathrm{x})$

$\mathrm{r}_{\mathrm{b}} ; \mathrm{r}_{\mathrm{t}}$

$\mathrm{R}^{2}$

$\mathrm{t}_{1} ; \mathrm{t}_{2} ; \mathrm{t}_{3}$

$\mathrm{V}_{\mathrm{f}} ; \mathrm{V}_{\mathrm{m}}$

$\mathrm{y}_{\mathrm{j}}^{\prime \prime}(\mathrm{x})$

Distance between the loading position and the pole top

Slope of the load - top deflection curves.

Constants of integration determined by the boundary conditions

Constants of integration determined by the boundary conditions

Fiber and matrix modulus of elasticity, respectively;

Longitudinal fiber modulus of elasticity in the transverse direction of the fiber

Modulus of elasticity in the fiber direction

Modulus of elasticity in the transverse direction

Young's modulus in the longitudinal direction of the $\mathrm{i}^{\text {th }}$ layer

Young's modulus in the longitudinal direction of the lamina which constitutes the zone (j)

Young's modulus in the longitudinal direction of the lamina which constitutes the zone $1 ; 2$; 3 , respectively

Flexural stiffness of the pole

Applied load

Ultimate applied load

Fiber and matrix shear modulus, respectively.

Shear modulus

Total length of the pole

Cantilever length (or free length) of the pole

Supported length of the pole $1 ; 2 ; 3$, respectively

Number of the zone considered, $(\mathrm{j}=1 ; 2 ; 3)$

Cumulated lengths of the zone $1 ; 2 ; 3$, respectively

Bending moment expression

Total number of layers in the zone (j)

Expression of the internal radius over the total length of the pole

Internal radius at the bottom butt and the top butt of the pole, respectively

Coefficient of regressing

Average wall thickness of the zone $1 ; 2 ; 3$, respectively

Fiber and matrix volume ratio, respectively

Curvature function in the zone (j) 


\begin{tabular}{|c|c|}
\hline $\mathrm{y}_{\mathrm{j}}^{\prime}(\mathrm{x})$ & Rotation function in the zone $(\mathrm{j})$ \\
\hline $\mathrm{y}_{\mathrm{j}}(\mathrm{x})$ & Displacement function in the zone (j) \\
\hline $\mathrm{y}_{3}\left(1_{3}\right)$ & $\begin{array}{l}\text { Lateral deflection at the loading position lo- } \\
\text { cated at a distance (a) from the top of the pole } \\
\text { under a load F. }\end{array}$ \\
\hline $\mathrm{y}_{3}\left(1_{3}\right)_{\max }$ & $\begin{array}{l}\text { Lateral deflection at the loading position lo- } \\
\text { cated at a distance (a) from the top of the pole } \\
\text { under the ultimate load } \mathrm{F}_{\mathrm{u}} \text {. }\end{array}$ \\
\hline$v_{\mathrm{lt}} ; v_{\mathrm{tl}}$ & Poisson's ratios \\
\hline$v_{\mathrm{f}} ; v_{\mathrm{m}}$ & Fiber and matrix Poisson's ratio, respectively; \\
\hline$\theta_{\mathrm{i}}$ & Fiber angle of the $i^{\text {th }}$ layer \\
\hline$\Delta$ & $\begin{array}{l}\text { Lateral deflection, determined experimentally } \\
\text { at the loading position located at a distance (a) } \\
\text { from the top of the pole under a load F. }\end{array}$ \\
\hline
\end{tabular}

\section{ACKNOWLEDGEMENTS}

The research reported in this paper was partially sponsored by the Natural Sciences and Engineering Research Council of Canada (NSERC) and by Hydro-Québec (Division Distribution). The authors also acknowledge the contribution of the Canadian Foundation for Innovation (CFI) for the infrastructure used to conduct testing. Special thanks to the manufacturer (FRE Composites, St-André d'Argenteuil, Qc, Canada) for providing full-scale FRP poles. The opinion and analysis presented in this paper are those of the authors. The technicians Gilles Levesque and Nicolas Simard participated in testing.

\section{REFERENCES}

[1] C. Ballinger, "Structural FRP Composites", ASCE Civil Engineering, vol. 60, pp. 63-66, July 1990.

[2] G. McClure, L. Boire and G. C. Carrière, "Applications of advanced composite materials in overhead power lines and telecom- munications structures", in advanced composite materials in bridges and structures: $1^{\text {st }}$ International Conference. Canadian Society for Civil Engineering, 1992, pp. 543-549.

[3] G. L. Derrick, "Fiberglass composite distribution and transmission poles", in Proceedings of the $3^{\text {rd }}$ International Conference on Power and Development in Afro-Asian Countries, 1996, pp. 1066-1073.

[4] Z. M. Lin, "Analysis of pole-type structure of fiber-reinforced plastics by finite element method", Ph. D. thesis, University of Manitoba, Manitoba, Canada, 1995.

[5] E. J. Barbero, and I. G. Raftoyiannis, "Euler Buckling of Pultruded Composite Columns". Compos. Struct., vol. 24, pp. 139-147, 1993.

[6] D. Polyzois, S. Ibrahim, and I. G. Raftoyiannis, "Performance of fiber-reinforced plastic tapered poles under lateral loading", Journal of composite materials, vol. 33, pp. 941-960, 1999.

[7] M. Gart, and G. Krambule, "Backyard pole replacement using fiberglass poles". Transm. Distrib. World, vol. 35, pp. 57-60, 1983.

[8] W. Crozier, J.P. Dussel, R. Bushey and J. West, "Evaluation of deflection and bending strength characteristics of fiber-reinforced plastic lighting standards", Report FHWA/CA/TL-95/14, Department of Transportation, New York, State of California, USA, 1995.

[9] California Department of Transportation, "Fiberglass Lighting Standards", Standard Special Provision 86.08.5, New York, State of California, USA, 1992,

[10] S. Ibrahim and D. Polyzois, "Ovalisation analysis of fiberreinforced plastic poles". Compos. Struct., vol. 45, pp. 7-12, 1999.

[11] American Society for Testing and Materials ASTM D 4923 - 01 "Standard Specification for Reinforced Thermosetting Plastic Poles", Annual Book of ASTM Standards, vol. 08.02, West Conshohocken, USA: ASTM International, 2005, pp. 726-735.

[12] American National Standard Institute. "Fiber-Reinforced Plastic (FRP) Lighting Poles". American National Standard for Roadway Lighting Equipment, USA. 136.20, 1990.

[13] California Department of Transportation. "Proposed California Test 683, Method for testing deflection and bending strength of fiberreinforced plastic poles", New York, State of California, USA, 1995.

[14] S. Ibrahim, D. Polyzois and K. Hassan, "Development of glass fiber reinforced plastic poles for transmission and distribution lines", Can. J. Civil Eng., vol. 27, pp. 850-858, 2000.

[15] A. Bazergui, T. Bui-Quoc, A. Biron, G. McIntyre, and C. Laberge, Résistance des matériaux, Québec, Canada : Presses Internationales Polytechnique, 2002, 715 p.

[16] D. Gay, Matériaux composites, Paris, France : Hermès, 1997, p. 672 . 